\title{
La dramatización de poemas infantiles: algunos ejemplos de trabajo para el aula de Educación Infantil y Primaria'
}

\author{
Children's Poetry Dramatization: \\ Some Examples to Work in Pre-school and Elementary School
}

\author{
MOISÉS SELFA SASTRE \\ Universidad de Lleida \\ MARÍA TERESA LLAMAZARES PRIETO \\ Universidad de León \\ España \\ mtllap@unileon.es \\ mselfa@didesp.udl.cat
}

(Recibido: 2O-O7-2OI5; aceptado: 2O-OI-2OI6)

Resumen. La poesía y el drama contribuyen, sin ninguna duda, a una educación literaria de calidad y a que el niño vaya desarrollando una buena expresión lingüística acorde a su edad de aprendizaje. Este artículo parte de la diferencia entre poesía dramatizable y poesía escenificable, conceptos importantes en la formación inicial y permanente del profesorado con el fin de estimular y favorecer la reflexión sobre la práctica educativa referida a la educación literaria. Además, se describe el procedimiento para dramatizar algunos textos poéticos. El resultado de la dramatización de estos poemas permite hablar de un juego dramático que favorece el contacto intenso y didáctico del niño con textos que han sido creados para él.

Palabras clave: poesía infantil; dramatización; escenificación; lengua oral.
Abstract. Poetry and drama, undoubtedly, contribute to a literary quality education and the student develops a good linguistic expression of age-appropriate learning. This paper is based on the difference between dramatic poetry and poetry to stage, important concepts for initial and continuing teacher training in order to stimulate and to encourage reflection on educational practice referring to the literary education. In addition, the procedure for dramatize some poems. The result of the dramatization of these poems can speak of a dramatic game that promotes intense and didactic child's contact with the texts that have been created for him. Further, it describes the procedure to dramatize some poems poetry. The result of the dramatization of these poems can to speak of a dramatic game that promotes intense and didactic child's contact with texts that have been created for him.

Keywords: children's poetry; dramatization; staging; oral language.

\footnotetext{
${ }^{\text {I }}$ Para citar este artículo: Llamazares Prieto, María Teresa y Selfa Sastre, Moisés (20I6). La dramatización de poemas infantiles: algunos ejemplos de trabajo para el aula de Educación Infantil y Primaria. Alabe 14. [www.revistaalabe.com]

DOI: Io.I5645/Alabe2OI6.I4.4
} 


\section{Introducción}

La educación literaria en la escuela ha girado tradicionalmente sobre la narración como género privilegiado de uso y explotación didáctica en el aula. Como formadores de futuros docentes de Educación Infantil y de Educación Primaria, queremos en este artículo fijar la mirada en la poesía y el drama no solo por los valores que cada uno de ellos tiene por separado, sino, y sobre todo, para lograr un abordaje conjunto de estas dos manifestaciones propias de la literatura que deben ser utilizadas en el aula para la formación literaria de los jóvenes estudiantes (Kelner y Flynn, 2006).

Cervera (I99O: I2I) abrió el camino al incluir los juegos de dramatización de textos poéticos en una de las áreas de encuentro del niño con la poesía, la relacionada con la función estética de la literatura. Ahora bien, no todos los textos poéticos son aptos para ser dramatizados. Por eso el objetivo de este artículo es proporcionar criterios de selección de textos poéticos infantiles susceptibles de ser dramatizados y distinguirlos, así, de aquellos a los que conviene más una escenificación o de los que, sencillamente, por su forma, sirvan para gustarlos mediante la recitación o declamación. En este sentido, convendrá, en primer lugar, delimitar el concepto de dramatización que sirve de base a nuestra propuesta y, a continuación, mostrar el procedimiento para transformar textos poéticos, que en su origen fueron pensados para ser recitados, en textos poéticos que pueden ser dramatizados sin perder su esencia poética.

Uno de los cuidados que debe tener cualquier docente es la selección de textos de calidad, es decir, textos cuya literariedad esté reconocida. Este cuidado nos dirigió hacia las antologías de poesía infantil para escoger los textos poéticos que íbamos a utilizar: desde la magnífica antología -en la que nos hemos centrado para este artículo- de A. Medina (i965) El silbo del aire, hasta otras más recientes y no menos valiosas como la de P. Cerrillo (2004), ¿Dónde está el niño que yo fui? Poemas para leer en la escuela.

El número de textos encontrados en esas antologías susceptibles de ser dramatizados es elevado, lo que hace inviable su inclusión en este trabajo, pero sí nos permite mostrar una tipología de textos poéticos a los que se puede aplicar un juego de dramatización.

\section{El concepto de dramatización: una cuestión terminológica}

El género narrativo ha sido y es el más utilizado en la escuela con enorme diferencia respecto a la poesía y el drama, los cuales siguen en pie a pesar de la marginación que padecen (Bernardi, 2OII). No obstante, es más que necesario reivindicar las enormes posibilidades de lectura y aprovechamiento, tanto estético como didáctico, de textos poéticos y dramáticos ya que estos facilitan la experimentación, el descubrimiento y el trabajo variado con palabras. 
La extraordinaria capacidad que la poesía tiene para dar voz al sentir y para comunicar la palabra revelada hace que esta sea especialmente adecuada para su trabajo en la escuela, aunque puedan constatarse ciertas distancias entre el sentir poético y la propia escuela (Cerrillo, 2004). El sentir poético no entiende que la poesía infantil tenga antes fines curriculares que artísticos. Dado que, para numerosos receptores, la escuela es casi la única ocasión para acercarse a la literatura, los textos que les acerquemos deberían tener un valor literario reconocido de manera que lo que sea infantil sea el destinatario, pero no la calidad de los textos (Andruetto, 2008). Y la finalidad de ese acercamiento debe ser, ante todo, la del placer por la lectura y la escucha del texto.

Algo similar ocurre con el drama, tanto para el destinado al público infantil como el destinado para su trabajo en la escuela. En este sentido es necesario que la escuela apueste por la puesta en práctica de proyectos dramáticos que inviten a la recuperación de la identidad y esencia de este género.

Uno de esos proyectos dramáticos es la dramatización. Hablamos de dramatización para referirnos a aquella actividad que utiliza la herramienta teatral en una práctica lúdica, orientada hacia sí misma y sin proyección exterior. En el mundo anglosajón esta actividad puede recibir el nombre de drama, creative drama, improvised drama y en el área francófona se conoce como jeu dramatique y expression dramatique (Tejerina, I994: II8). Motos y Tejedo (r999: r9) añaden a estos conceptos otros términos (juego de expresión, juego teatral, role playing, sociodrama, improvisación...) especificando que, aunque todos tienen un origen teatral, la finalidad con la que se aplican es distinta.

Tanto Motos y Tejedo (I999) como Tejerina (I994) han comparado las características que definirían a la dramatización y al juego dramático. Según estos autores, no hay diferencias entre estas dos técnicas que se han distinguido solamente por un problema de traducción al castellano de los términos creative dramatic y jeu dramatique. La palabra utilizada comúnmente en nuestro ámbito educativo y la que ha aparecido en diversas leyes educativas desde la Ley General de Educación de i97o (Núñez y Navarro, 2007: 229) es la de dramatización, pero la usaremos como sinónima de juego dramático porque ambas hacen referencia a una forma de expresión dramática estructurada que utiliza la acción para la mejora de la comunicación y la potenciación de la creatividad. Por medio de estas técnicas se busca que el niño desarrolle sus capacidades perceptivas y expresivas, especialmente la expresión de sí mismo en relación con los otros y con el mundo (Núñez y Navarro, 2007: 232).

La palabra dramatización tiene un doble sentido (Tejerina, I994: I2O-I):

I) Dramatización entendida como proceso mental en el que se transforma en materia dramática algo que no lo era originariamente (en nuestro caso, un poema). Se trata de producir una acción convencionalmente repetida, esto es, de crear drama en su sentido etimológico que es el de acción, con finalidad artística o lúdica.

2) La dramatización como resultado del proceso anterior. Es la reproducción de la acción en la que intervienen no solo la expresión lingüística, sino también la expresión corporal, la expresión plástica y la expresión rítmico-musical, por lo que estaríamos ante la representación de lo que se ha dramatizado. 
Usaremos la palabra dramatización con estos dos sentidos, lo que nos conduce a considerar que esta adquiere categoría privilegiada entre las demás actividades creativas a las que puede dedicarse el niño porque suma todos los recursos expresivos y lo hace con tal economía de medios que, en principio, no necesita absolutamente nada fuera de su propio cuerpo (López, Jerez, Encabo, 20IO: I6). El proceso creativo pasa por tres fases lógicamente sucesivas: selección, asociación y organización. La selección supone escoger formas, situaciones, hechos, palabras... ya existentes que, de forma más o menos consciente, asociamos con otras por distintos procedimientos de combinación, de transformación, de connotación o de reelaboración. Lo cierto es que el resultado de estos procesos, en ocasiones entrelazados entre sí, reclama una nueva organización del resultado obtenido, de tal modo que lo que se consigue es una realidad nueva que, lógicamente, se diferencia bastante de la primitiva seleccionada que sirvió de punto de partida (López, Jerez y Encabo, 20IO: 27-3I). Por eso coincidimos con Bolton (I986: I8) cuando afirma que la dramatización en la educación no es el estudio de los textos dramáticos ni la representación de una obra escolar, aunque estas acciones pueden ser parte de ella; es esencialmente un proceso, de tipo dramático, que enfoca los sentimientos y el intelecto del alumnado para conseguir objetivos educativos.

La dramatización y el teatro tienen muchos puntos en común, pero también importantes diferencias que, desde el punto de vista didáctico, conviene resaltar. Un estudio pormenorizado de tales diferencias puede verse en Cervera (I986) y en López, Jerez y Encabo (20I0: 19). De entre ellas, las que resaltaríamos por su vinculación con nuestro estudio son las tres siguientes:

a) Respecto a los participantes, en la dramatización no hay actores sino que los niños juegan a hacer como si...; por eso se dice que hay jugadores, una de cuyas características más singulares es que se van alternando con los observadores. En el teatro, en cambio, encontramos actores bien diferenciados del público.

b) En cuanto al texto, habitualmente en el teatro hay un texto fijado de antemano mientras que en la dramatización no lo hay, sino que se parte de un esquema de acción, con la improvisación y las aportaciones personales como procedimientos fundamentales. En nuestra propuesta, esta diferencia desaparece en parte ya que sí partimos de un texto (el texto poético que hayamos escogido para ser dramatizado), pero permanecen las aportaciones personales presentes en la interpretación que cada educando hace del texto.

c) La tercera diferencia es que hay que concebir la dramatización como un proceso mientras que el teatro es un resultado. En la dramatización interesa el proceso que se lleva a cabo en el aula, incluida la construcción de decorados y la caracterización de los personajes (muy simples e imaginativos, en general). Con suerte, estaría bien contar con un aula específica de dimensiones amplias En el teatro se busca el espectáculo que exige una cuidada puesta en escena en un espacio ad hoc. 


\section{Poesía, dramatización y el desarrollo de la expresión lingüística}

Se ha contemplado la dramatización como un instrumento para el desarrollo personal y social y como un medio ideal para la adquisición y desarrollo de las destrezas lingüísticas (Seely, ı976; O’Neill y Lambert, ı982; Cervera, I986). La dramatización es una herramienta privilegiada para el desarrollo de diversas áreas curriculares porque agrupa todos los recursos expresivos del ser humano al coordinar la expresión lingüística, corporal, plástica y rítmico-musical que en los currícula escolares suelen cultivarse por separado. La dramatización ofrece la oportunidad de manejar los cuatro tipos de expresión de manera simultánea unas veces y de forma sucesiva otras, añadiendo la motivación que, para el niño, supone su carácter lúdico (Tejerina, I994: г27).

Los decretos actuales que regulan las enseñanzas mínimas en Educación Infantil y el currículum para la Educación Primaria también se refieren a la dramatización explícitamente como un contenido que debe trabajarse y evaluarse en estas dos etapas educativas. Así, el Real Decreto I630/2006, de 29 de diciembre, que establece las enseñanzas mínimas del segundo ciclo de Educación Infantil, dentro de los contenidos del Bloque I (Lenguaje Verbal), afirma que es necesario trabajar la dramatización de textos literarios y el disfrute e interés por expresarse con ayuda de recursos extralingüísticos. Paralelamente, en el Bloque 4 (Lenguaje Corporal), se explicita la necesidad de cultivar la participación en actividades de dramatización, danzas, juego simbólico y otros juegos de expresión corporal.

Por su parte, el Real Decreto I26/20I4, de 28 de febrero, por el que se establece el currículo básico de la Educación Primaria, entre los contenidos propios del Bloque I Comunicación oral: hablar y escuchar que deben trabajarse en el área de Lengua Castellana y Literatura está el de procurar dramatizaciones de textos literarios adaptados a la edad y de producciones propias. Además, en el Bloque 5 (Educación Literaria) se habla explícitamente de cultivar la dramatización y lectura dramatizada de textos literarios y se utiliza, como criterio de evaluación, la participación con interés del discente en dramatizaciones de textos literarios adaptados a la edad y de producciones propias o de los compañeros, utilizando adecuadamente los recursos básicos de los intercambios orales y de la técnica teatral.

Son numerosos los trabajos que muestran las bondades de la dramatización en el enriquecimiento de las capacidades expresivas y lingüísticas del niño (Motos, I992; Moreno, I999; Núñez y Navarro, 2007), hasta tal punto que se ha vinculado esta técnica a los avances en metodología para la adquisición de las destrezas orales en la enseñanza de segundas lenguas, sobre todo en el mundo anglosajón, pero también de la lengua materna. Usada correctamente, la dramatización puede mejorar la fluidez en situaciones de interacción lingüística, el aprendizaje de funciones comunicativas, de vocabulario, de pronunciación y prosodia de forma plenamente contextualizada (Pérez Gutiérrez, 2004: 78). Si se utiliza un poema como punto de partida para la dramatización, estaremos reforzando la palabra en un contexto creado por un experto en el uso de la lengua, facili- 
taremos la asimilación de modelos lingüísticos y estimularemos la creación de lenguaje debido a la función estética presente en ese poema.

Cuando dos o más niños juegan a representar por medio de la palabra, la comunicación oral se convierte en un importante factor en el éxito de la simulación escenificada. Este tipo de juego se constituye así en un poderoso y placentero instrumento de capacitación lingüística (Tejerina, r997: 76). Los valores bien conocidos de la poesía como la sonoridad, los juegos de palabras, la expresividad, el enriquecimiento del vocabulario... se ponen al servicio del diálogo, de la conversación, entendida como la forma más importante de interacción entre hablantes y oyentes en la que los papeles de hablante y oyente se intercambian de continuo.

En este artículo, queremos detenernos en este tipo de objetivos comunicativos. La dramatización de poesías aporta beneficios indudables al desarrollo de la lengua oral porque el niño es un aprendiz de emisor, lo que condiciona tanto el contenido como la forma de sus mensajes. Respecto a la forma, cualquier texto literario aporta, en el plano léxico, vocabulario que amplía su conocimiento del mundo y, en el plano sintáctico, frases cuya estructura es más variada y compleja que las que habitualmente utiliza el aprendiz; en lo pragmático, al fin, el texto y su dramatización le da ocasión de utilizar la lengua en situaciones y con interlocutores variados, con los que debe esmerar su pronunciación y entonación (Valenzuela, 2004: 2IO). Pero no solo esto, sino que al proporcionarles un diálogo literario, colocamos al alumnado en la situación de vivenciar el principio de cooperación que, según Grice (Escandell, r996: 79), rige las intervenciones de cada interlocutor en el trascurso de una conversación para evitar que la misma sea inconexa y absurda. Es un principio que se desarrolla en categorías y máximas específicas que resumimos a continuación:

a) intervenir en el momento oportuno y no en cualquier momento;

b) dar la información que sea exigida pero no más de lo que nos piden;

c) intentar que nuestra contribución sea verdadera, no decir algo de lo que no se tengan pruebas suficientes;

d) ser pertinentes, es decir, que la contribución sea coherente con el tema que se esté tratando;

e) ser claro, preciso y ordenado.

En los intercambios comunicativos, el educando debe aprender que su contribución debe ser no solo correcta lingüísticamente hablando, sino adecuada porque la adquisición de una lengua es un proceso de socialización, un modelo transaccional entre un aprendiz y un usuario más experto de la lengua según el cual se establece un intercambio entre ambos que permite al niño comprender las reglas del diálogo y no tanto la sintaxis o la semántica (Owens, 2003: 59). Dramatizar poemas proporciona la situación idónea para un intercambio correcto, desde el punto de vista lingüístico, adecuado, desde el punto de vista pragmático y estético desde el punto de vista literario. Y en relación a las funciones del lenguaje, nos permite abordar el modelo imaginativo (hagamos como si...) 
del que habla Halliday (I982) o el uso simbólico o imaginativo del que habla Tough (I987: 92), funciones que constituyen uno de los pilares básicos de la didáctica de la literatura: apropiarse del lenguaje poético y leer sin ninguna otra finalidad que el goce estético.

\section{Dramatización y escenificación}

Cervera (I990:I2I) habla de tres áreas de encuentro del niño con la poesía: leer y recitar.

a) La primera sería la lectura y la declamación; es el uso más habitual de la poesía:

b) La segunda área sería la canción, que aúna texto, melodía y ritmo.

c) La tercera área sería el juego, con diversos tipos, entre los que incluye los juegos de dramatización que utilizan textos poéticos (y de canciones).

En la dramatización de poemas, efectivamente, aparece el juego dramático puesto que convertimos un texto que no es dramático en un texto con estructura dramática, en el que son perceptibles los elementos básicos del drama: los personajes, el conflicto o relación que se establece entre ellos, el tiempo, el espacio, el argumento y el tema. Aunque esta conversión es una labor que corresponde fundamentalmente al docente, se puede hacer partícipe a los educandos, quienes al representar el poema en el aula entran de lleno en la primera de las áreas de encuentro citadas en las líneas anteriores al tener, necesariamente, que memorizar el texto y declamarlo.

Una de las premisas inexcusables que debe tener en cuenta el docente es mantener la integridad del poema: el principal objetivo es acercar la poesía al niño y hacerlo en forma de juego, pero si eso obliga a transformar el texto en demasía significará que ese texto no era apropiado para ser dramatizado porque no todos los textos lo son.

Desde este punto de vista habría que distinguir entre dramatización y escenificación. Como venimos diciendo, la dramatización consiste en crear estructura dramática y lo específico de la estructura dramática es la presencia de sus elementos fundamentales: personajes, conflicto, espacio, tiempo, argumento y tema. La escenificación, por el contrario, no crea estructura dramática. Gracias a ella la representación toma apariencia dramática, sin alcanzar su estructura, porque los personajes no toman la palabra y suele haber un narrador que cuenta la acción. Además, la escenificación presenta elementos verbales que en sí mismos no suponen la reproducción de una acción (Cervera, I99O:I27).

En consecuencia, y dejando a un lado la poesía dramática, es decir, aquella cuyo autor destina a la escena ya desde su génesis, podemos hablar de:

a) Poemas dramatizables. No están escritos para ser representados pero sus características formales permiten dotarles de estructura dramática. Cervera (I990: ı27) afirma que son textos dramatizables porque reúnen en sí los elementos fundamentales del drama que acabamos de citar y suponen la reproducción directa e inmediata de una acción, sin intermediación de un narrador.

b) Poemas escenificables. No tienen estructura dramática porque solo narran un 
acontecimiento o el autor manifiesta sus sentimientos ante un hecho o presentan meramente elementos verbales que en sí no suponen la reproducción directa e inmediata de una acción. Cervera (I990: I27) los califica de escenificables porque permiten un juego paradramático o escénico, es decir, mientras una voz (el narrador) recita la poesía, unos actores que nunca tomarían la palabra, se moverían en escena siguiendo el texto poético. Se trata, pues, de un juego de apariencia dramática porque no es una representación directa de una acción, no son los personajes los que la llevan adelante, sino un narrador. Y el narrador no es un elemento del drama.

Por ejemplo, en la siguiente poesía de A. Marqueríe (Medina, I965: II, 57), un narrador traslada a los oyentes o lectores la felicidad de unos cabritillos que "hacen novillos". Mientras una persona la recita, podría haber en escena tres, cuatro... niños que escenificarían lo que hacen los cabritillos (saltar retozones, mordisquear...). Es el relato de una escena, pero los personajes no hablan:

\section{Los cabritillos}

Se fueron de la escuela

los cabritillos

y triscan retozones

como chiquillos;

rumian las ramas verdes

a dos carrillos;

y son de caramelo

sus cuatro ojillos,

gozando en su diablura

de "hacer novillos".

Se podría afirmar que, prácticamente, cualquier poema es escenificable pero no así dramatizable. Dentro del grupo de poesías infantiles susceptibles de ser dramatizadas, que constituyen el objetivo de este trabajo, encontramos varios tipos:

I) Poesías totalmente dialogadas, sin narrador.

Son muy sencillas de dramatizar puesto que su propia estructura permite asignar el nombre del personaje antes de su intervención. Veamos algunos ejemplos: 


\begin{tabular}{|l|l|}
\hline \multicolumn{1}{|c|}{ TEXTO ORIGINAL } & \multicolumn{1}{c|}{ TEXTO DRAMÁTICO } \\
\hline \multicolumn{1}{|c|}{ Canción tonta } & (En escena, madre sentada, bordando; \\
Mamá. & un niño sentado a sus pies con juguetes) \\
Yo quiero ser de plata. & HIO: -Mamá. \\
Hijo, & Yo quiero ser de plata. \\
Tendrás mucho frío. & MADRE: -Hijo, \\
Mamá. & tendrás mucho frío. \\
Yo quiero ser de agua. & HIJO: -Mamá. \\
Hijo, & Yo quiero ser de agua. \\
Tendrás mucho frío. & MADRE: -Hijo, \\
Mamá. & tendrás mucho frío. \\
Bórdame en tu almohada. & HIJO: -Mamá. \\
¡Eso sí! & Bórdame en tu almohada. \\
¡Ahora mismo! & MADRE: -¡Eso sí! \\
F. García Lorca (Medina, I985: I, 85) & ¡Ahora mismo! \\
\hline
\end{tabular}

En la poesía de Lorca, las dos últimas intervenciones de los personajes nos permiten imaginar la escena que se describe en la acotación inicial: si la madre puede bordar a su hijo en la almohada mientras dialoga con él, se infiere que está bordando en ese momento y esta es una labor que se suele hacer dentro del propio hogar. En la siguiente de Á. Figuera, de estructura paralela, no se adivina un espacio tan claramente, de manera que podríamos buscar la aportación individual y preguntarles a los educandos: "si el niño pide una piedra a su madre y esta le da dos, ¿dónde pueden estar madre e hijo para tenerlas a mano?". Como caben varias posibilidades (en la playa, en un camino, en un parque, a la orilla de un río...), entre todos puede decidirse el lugar. 


\begin{tabular}{|c|c|}
\hline TEXTO ORIGINAL & TEXTO DRAMÁTICO \\
\hline Antojos & $\begin{array}{l}\text { (En escena, madre hijo paseando a la orilla } \\
\text { de un río, al anochecer) }\end{array}$ \\
\hline -Mamá, yo quiero la luna... & HIJO: -Mamá, yo quiero la luna... \\
\hline -Hijo mío, está muy alta... & MADRE: -Hijo mío, está muy alta... \\
\hline -Mamá, yo quiero un caballo... & HIJO: -Mamá, yo quiero un caballo... \\
\hline -Hijo, si no tienes cuadra... & MADRE: -Hijo, si no tienes cuadra... \\
\hline -Mamá, quiero un pececito... & HJJO: -Mamá, quiero un pececito... \\
\hline -¿Y quién lo saca del agua?... & MADRE: -¿Y quién lo saca del agua?... \\
\hline -Mamá, yo quiero una piedra... & HIJO: -Mamá, yo quiero una piedra... \\
\hline -Eso, sí... Ten dos, y calla. & MADRE (se agacha y coge dos piedras): \\
\hline A. Figuera (Medina, I985: I, 30) & -Eso, sí... Ten dos, y calla. \\
\hline
\end{tabular}

En el texto siguiente, A. Nervo no deja ver quién es el interlocutor del niño, de manera que se puede pedir a los educandos que hagan hipótesis y que decidan quién es la persona que le está proponiendo al niño cantar una canción y cómo se podría caracterizar a ese personaje: un maestro y llevaría unas gafas, un payaso con zapatones, una presentadora de un concurso de televisión con un chaleco brillante... 


\begin{tabular}{|c|c|}
\hline TEXTO ORIGINAL & TEXTO DRAMÁTICO \\
\hline Los sentidos & (En escena, un director de orquesta con batu- \\
\hline Niño, vamos a cantar & ta y un niño) \\
\hline una bonita canción; & DIRECTOR: -Niño, vamos a cantar \\
\hline yo te voy a preguntar, & una bonita canción; \\
\hline tú me vas a responder. & yo te voy a preguntar, \\
\hline Los ojos, ¿para qué son? & tú me vas a responder. \\
\hline -Los ojos son para ver. & Los ojos, ¿para qué son? \\
\hline - ¿Y el tacto? -Para tocar. & NIÑO: -Los ojos son para ver. \\
\hline -¿Y el oído? -Para oír. & DIRECTOR: - ¿Y el tacto? \\
\hline - ¿Y el gusto? -Para gustar. & NIÑO: -Para tocar. \\
\hline -¿Y el olfato? -Para oler. & DIRECTOR: - ¿Y el oído? \\
\hline - ¿Y el alma? -Para sentir, & NIÑO: -Para oír. \\
\hline para querer y pensar. & DIRECTOR: -¿Y el gusto? \\
\hline \multirow{6}{*}{ A. Nervo (Medina, I985: I, 86) } & NIÑO: -Para gustar. \\
\hline & DIRECTOR: -¿Y el olfato? \\
\hline & NIÑO: -Para oler. \\
\hline & DIRECTOR: -¿Y el alma? \\
\hline & NIÑO: -Para sentir, \\
\hline & para querer y pensar. \\
\hline
\end{tabular}

En la imaginativa poesía Nube, de Gómez Yebra, antes de asignar los personajes, los propios educandos deberían realizar una sencilla inferencia acerca de quiénes son los dos interlocutores: un abuelo y su nieto o su nieta. El espacio apunta al aire libre, pero también se podría acordar dónde exactamente. 


\begin{tabular}{|l|l|}
\hline \multicolumn{1}{|c|}{ Nube } & \multicolumn{1}{|c|}{ TEXTO DRAMÁTICO } \\
\hline -Alta la nube, volando, & (Abuelo y nieto, tumbados boca arriba en un \\
se para de vez en cuando. & prado, contemplando el cielo. Pasa una nube) \\
-jSi yo pudiera llegar & ABUELO: -Alta la nube, volando, \\
hasta el cielo! Dame, abuelo, & se para de vez en cuando. \\
un avión con un hangar. & NIETO: -iSi yo pudiera llegar \\
-Mira la nube, ya quieta & hasta el cielo! Dame, abuelo, \\
cobra forma de cometa. & un avión con un hangar. \\
-¡Un avión, pronto, un avión & ABUELO: -Mira la nube, ya quieta \\
de papel! Quiero alcanzar & cobra forma de cometa. \\
su algodón subido en él. & NIETO (inquieto): \\
-Si parece que te guiña & -¡Un avión, pronto, un avión \\
con sus ojillos de niña... & de papel! Quiero alcanzar \\
-¡Déjame que llegue allí & su algodón subido en él. \\
sin tardar! ¿La he de dejar & ABUELO: -Si parece que te guiña \\
si me está llamando a mí? & con sus ojillos de niña... \\
-Nube blanca, nube doble, & NIÑO (se levanta y salta) \\
¡El amor te hace más noble! & -¡Déjame que llegue allí \\
A. Gómez Yebra (Cerrillo, 2OO4: I26) & sin tardar! ¿La he de dejar \\
& si me estállamando a mí? \\
& ABUELO: -Nube blanca, nube doble, \\
& ¡El amor te hace más noble! \\
\hline
\end{tabular}

Un caso especial de textos totalmente dialogados, sin narrador, son algunas de las canciones de juego que forman parte del folclore. Sean canciones de corro, de filas, de serpenteos..., se trata de composiciones anónimas que se han transmitido de generación en generación de forma oral (de ahí las variantes que podemos encontrar) y que se cantan acompañadas de alguna acción. Algunas de ellas son verdaderos diálogos que se 
representan en presencia de todos los participantes en el juego. Así, en el juego de corro Jardinera, las personas que participan en el juego se dirigen de forma coral a la niña que está en el medio (la jardinera) para indicarle que escoja una flor (cualquiera de las del corro); una vez escogida, se produce el diálogo entre la jardinera y la persona escogida, donde la nrimera da razones ame iustifican suelección v la seounda aoradece el honor de

\section{TEXTO ORIGINAL}

\section{Jardinera}

Jardinera, tú que entraste

en el jardín del amor,

de las plantas que regaste

dime cuál es la mejor.

-La mejor es una rosa,

que se viste de color,

del color que se le antoja,

y verde tiene la flor.

Tres hojitas tiene verdes

y las demás encarnadas,

$\mathrm{y}$ a ti prefiero entre todas,

que eres la más colorada.

-Gracias te doy, jardinera,

porque me hayas elegido,

entre tantas como hay

a mí sola has preferido.

Popular (Medina, I985: I, I2)

\section{TEXTO DRAMÁTICO}

(Todos en corro, una niña en el medio)

TODOS: -Jardinera, tú que entraste

en el jardín del amor,

de las plantas que regaste

dime cuál es la mejor.

JARDINERA (Una rodilla en tierra, de-

lante de la persona que elija):

-La mejor es una rosa,

que se viste de color,

del color que se le antoja,

y verde tiene la flor.

Tres hojitas tiene verdes

y las demás encarnadas,

y a ti prefiero entre todas,

que eres la más colorada.

PERSONA ESCOGIDA (Cambia la posición con la jardinera):

-Gracias te doy, jardinera,

porque me hayas elegido,

entre tantas como hay

a mí sola has preferido.

Por último, dentro de este grupo de poemas sin narrador, habría que incluir tam- 
bién aquellos poemas en los que un interlocutor se dirige a una segunda persona que no interviene en la conversación, lo que convierte al texto en un monólogo que se podría recitar sin más; no obstante, podemos proponer un juego dramático con la presencia de ese tú en escena, mudo, pero que justifica la situación.

En el poema de Alberti, habría que decidir quién es el que increpa al carretero recordándole todas las cosas que tiene a su favor. Se puede jugar con la rima y las profesiones (minero, barrendero, panadero...) e, imitando al poeta, dialogar sobre las ventajas

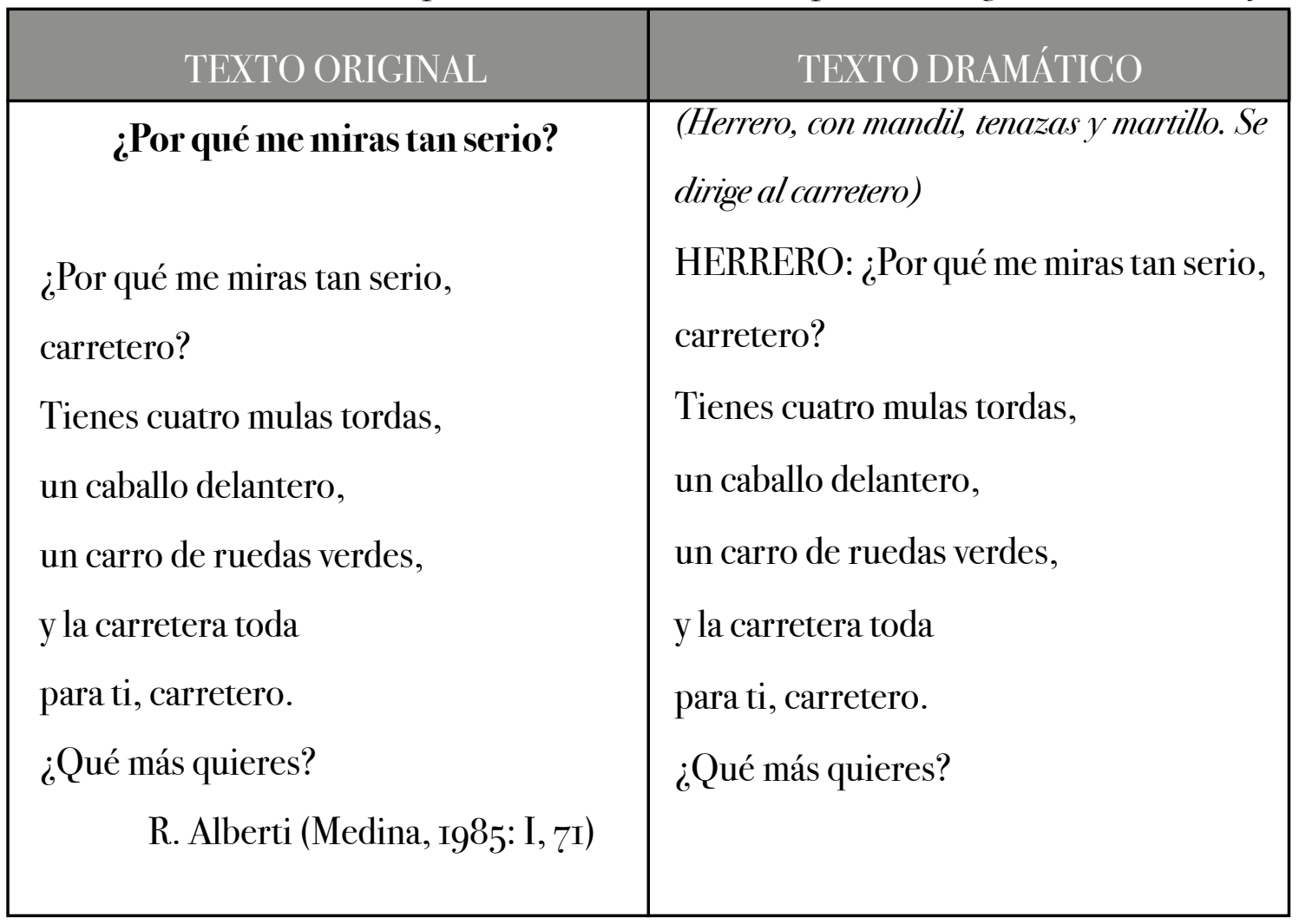

La conocidísima y rítmica Ronda del zapatero, de G. Berdiales, es otro ejemplo de este grupo de textos sin narrador que se dirigen a una segunda persona, como lo demuestran los posesivos de segunda persona (tu rincón, tu martillo, tus suelas). El marcado ritmo de la poesía invita a una representación en la que el monólogo del cliente insatisfecho puede ser acompañado de golpes rítmicos del zapatero que, sin decir una palabra, sigue trabajando con sus suelas mientras su interlocutor habla. 


\begin{tabular}{|c|c|}
\hline TEXTO ORIGINAL & TEXTO DRAMÁTICO \\
\hline Ronda del zapatero & (Zapatero sentado, arreglando suelas \\
\hline Tini-tane tini-tane & de un zapato) \\
\hline tipi-tape, tipitón, & CLIENTE: -Tipi-tape, tipi-tape, \\
\hline tipi-tape, zape-zape, & tipi-tape, tipitón, \\
\hline zapatero remendón. & tipi-tape, zape-zape, \\
\hline Tipi-tape todo el día. & zapatero remendón. \\
\hline todo el año tipitón, & Tipi-tape todo el día, \\
\hline tipi-tape, macha-macha, & todo el año tipitón, \\
\hline machacando en tu rincón. & tipi-tape, macha-macha, \\
\hline Tipi-tape en tu banqueta, & machacando en tu rincón. \\
\hline tipi-tape, tipitón & Tipi-tape en tu banqueta, \\
\hline tipitón con tu martillo & tipi-tape, tipitón \\
\hline macha-macha-machacón. & tipitón con tu martillo \\
\hline ¡Ay, tus suelas, zapa-zapa & macha-macha-machacón. \\
\hline zapatero remendón; & ¡Ay, tus suelas, zapa-zapa \\
\hline ay tus suelas, tipi-tape & zapatero remendón; \\
\hline duran menos que el cartón! & ay tus suelas, tipi-tape \\
\hline Tipi-tape, tipi-tape, & duran menos que el cartón! \\
\hline tipi-tape, tipitón. & Tipi-tape, tipi-tape, \\
\hline G. Berdiales (Medina, I985: I, 7I) & tipi-tape, tipitón. \\
\hline
\end{tabular}

\section{2) Poesías dialogadas con narrador}

Desde el momento en que hay narrador, teóricamente estamos ante poemas que no son dramatizables. Pero podemos realizar alguna transformación para convertirlos en dramatizables. Los textos más aprovechables para esa transformación son aquellos en los que la narración es muy breve y además no se entremezcla con el diálogo. Este es el caso del Romance de la Virgen y el olivo, de F. Muelas (Medina, I985: II, II8): el narrador 
aparece solo en los dos primeros versos ("Tres aceitunas colgaban / de las ramas del olivo") y luego da paso al diálogo que se establece entre la Virgen María y el dueño del olivo. Esta intervención del narrador es fácilmente transformable en una acotación como la siguiente: (Aparece un olivo del que cuelgan tres aceitunas. La Virgen María se acerca y las acaricia).

En otros casos, es factible poner en boca de algunos personajes la intervención

\begin{tabular}{|c|c|}
\hline TEXTO ORIGINAL & TEXTO DRAMÁTICO \\
\hline El burro y la escuela & $\begin{array}{l}\text { (Varios personajes en semicírculo. La maestra } \\
\text { señala y pregunta) }\end{array}$ \\
\hline Una v una, dos. & MAESTRA: -Una y una... \\
\hline Dos y una, seis. & NIÑA: -¡Dos! \\
\hline El pobre burrito & MAESTRA: - Dos y una... \\
\hline contaba al revés. & BURRITO: -¡Seis! \\
\hline -¡No se lo sabe! & TODOS: - ¡No se lo sabe! \\
\hline -Sí me lo sé. & BURRITO: -Sí me lo sé. \\
\hline -¡Usted nunca estudia! & MAESTRA: -¡Usted nunca estudia! \\
\hline Dígame por qué. & Dígame por qué. \\
\hline -Cuando voy a casa & BURRITO (triste): -Cuando voy a casa \\
\hline no puedo estudiar; & no puedo estudiar; \\
\hline mi amo es muy pobre, & mi amo es muy pobre, \\
\hline hay que trabajar. & hay que trabajar. \\
\hline Trabajo en la noria & Trabajo en la noria \\
\hline todo el santo día. & todo el santo día. \\
\hline ¡No me llame burro, & ¡No me llame burro, \\
\hline profesora mía! & profesora mía! \\
\hline G. Fuertes (Medina, I985: I, 74) & \\
\hline
\end{tabular}

Otra posibilidad es mantener el narrador que se constituiría en un personaje más, el que introduce la acción. Entonces hablaríamos de una semidramatización porque la 


\begin{tabular}{|l|l|}
\hline \multicolumn{1}{|c|}{ LEXTO ORIGINAL } & \multicolumn{1}{|c|}{ TEXTO SEMIDRAMÁTICO } \\
\hline \multicolumn{1}{|c|}{ La ardilla corre. } & $\begin{array}{l}\text { (Aparecen paseando niño y madre; ardilla mo- } \\
\text { viéndose inquieta mientras habla el narrador) }\end{array}$ \\
La ardilla vuela. & NARRADOR: -La ardilla corre. \\
La ardilla salta & La ardilla vuela. \\
como locuela. & La ardilla salta \\
-Mamá, la ardilla & como locuela. \\
¿no va a la escuela? & NIÑO (dirigiéndose a su madre): \\
Ven, ardillita, & -Mamá, la ardilla \\
tengo una jaula & ¿no va a la escuela? \\
que es muy bonita. & (dirigiéndose a la ardilla) \\
-No yo prefiero & Ven, ardillita, \\
mi tronco de árbol & tengo una jaula \\
y mi agujero. & que es muy bonita. \\
\multicolumn{1}{|c|}{ A. Nervo (Medina, I985: I, 58) } & ARDILLA: -No yo prefiero \\
& mi tronco de árbol \\
& y mi agujero. \\
\hline
\end{tabular}

Cuando en un poema predomina la narración sobre el diálogo, no se debería utilizar ese texto para hacer un juego de dramatización. Por ejemplo, Monigote pintado, de J. González Estrada (Medina, 1985: I, 37), es apropiado para recitar, pero no para dramatizar porque la intervención directa de los personajes es exigua:

Monigote pintado.

Con dos piernas

y dos brazos...

Con dos ojos redondos,

Y una risa muy larga

que le estira los labios...

-¿Dónde están las orejas?

-Se me olvidaron...

asombrados 
Tampoco son apropiados para dramatizar aquellos poemas en los que la narración y el diálogo se entremezclan, como en este de J. González Estrada (Medina, 1985: I, 94):

\section{La hormiga cojita}

Rota la patita,

sin poder andar,

la pobre hormiguita

se puso a llorar:

-A ver cómo voy,

cojita que estoy...!

La oyó un caracol:

-No llore, señora,

la llevo yo...

A ochenta por hora pasó una tortuga:

-¡Suba, suba, suba...!

Pero un gorrión

la cogió en su pico

y se la llevó...

Así es como fue

la pobre hormiguita

cojita

volando a Belén.

\section{Procedimiento para la dramatización de poemas.}

Si nuestra finalidad es crear una estructura dramática partiendo de un poema adecuado a ese fin, debemos establecer una secuencia de momentos ordenados que hemos tratado de ejemplificar con los textos que anteceden y que intentamos sintetizar a continuación. Nuestra intención previa (concepto acuñado por Fábregas, I975: I9) es que el educando interactúe con textos poéticos buscando un acercamiento lúdico a los mismos a través de su dramatización. El procedimiento conllevaría los siguientes pasos:

I) Elección, por parte del docente, de la poesía que se va a proponer para dramatizar. Los criterios para seleccionar el material poético serían:

-La calidad literaria del texto, criterio que aseguramos utilizando como yacimiento de búsqueda las antologías de poesía infantil.

-Poesías totalmente dialogadas, esto es, sin narrador.

-Poesías dialogadas con narrador, siempre y cuando la intervención de este sea mínima y no se entremezcle con el diálogo.

Partiendo siempre del valor estético, usamos criterios formales cuyo resultado es una miscelánea de textos (acorde con las antologías donde buscamos): podemos encontrar textos de tradición oral y textos de autor, poesías de contenido lírico o narrativo, villancicos, juegos populares...

2) Presentación del texto al alumnado, mediante la lectura o el recitado del docente o de los propios alumnos, en función de su edad. 
3) Ronda de impresiones y opiniones sobre todo lo que el texto haya sugerido o reflejado en relación a los personajes (¿quiénes son?), el conflicto (¿qué relación hay entre ellos?, ¿para qué dialogan?), el espacio y el tiempo (sopesando que estos elementos del drama podrían perfectamente compartir la indeterminación espacial y temporal de los cuentos infantiles).

4) La planificación de la dramatización, con la asignación de personajes. Aunque no sea necesaria una caracterización pormenorizada del personaje (no estamos haciendo una obra de teatro), este sería el momento de determinar los medios de expresión que se utilizarían. La expresión lingüística es la base, pero se podrían añadir la expresión corporal o cualquier objeto o elemento simbólico que sirviera para acercar el personaje tanto al intérprete como a los que están viendo y escuchando la puesta en escena de la poesía: un collar para una madre, o, tal vez, recogerle el pelo en un moño; un juguete para un niño; una cacha para un abuelo; un babi a modo de capa para representar las alas de cualquier pajarito...

5) La dramatización propiamente dicha.

6) La evaluación de la dramatización en la que, aun valorando aspectos puntuales de la lengua oral como son la dicción, vocalización y entonación, debería centrarse en comprobar que la elección del texto ha sido significativa para el niño más allá de ser una tarea escolar porque, como dice Montes (2007: I6), un maestro debería ser consciente de que, por mucho saber y muchas lecturas que tenga en su espacio personal, no será el constructor del sentido del otro.

\section{Conclusiones}

La dramatización es un proceso de creación que transforma en materia dramática un texto que no lo era originariamente. Es bien conocido que al dramatizar un texto se utilizan diversos tipos de expresión: lingüística, corporal, plástica y rítmico-musical, que facilitan un acercamiento lúdico al texto seleccionado al asumir una interacción entre personajes y saborear el valor comunicativo de esta: cómo hablan, qué preguntan, qué sienten, cómo establecen un diálogo.... En este sentido, nos servimos de la dramatización para mediar entre el texto y el niño, buscando su disfrute y el desarrollo de la comunicación en los educandos de Educación Infantil y de Primaria.

Uno de nuestros cuidados como formadores de futuros docentes de Educación Infantil y Educación Primaria es proporcionar herramientas de trabajo a los profesionales que deben actuar como mediadores para acercar la poesía a los niños, siendo conscientes de que se adentrarán en un territorio difícil de recorrer pero fácil de sentir.

En este artículo, ofrecemos un conjunto de poemas susceptibles de ser dramatizados con la finalidad de que puedan ser trabajados en las aulas de Educación Infantil y Educación Primaria. Junto al texto original, ofrecemos nuestra propuesta de texto dramatizable, no como un procedimiento que a modo de receta puede trasladarse directa- 
mente al aula, sino como una puerta que permite la incorporación al texto de vivencias personales tanto al leerlo como al decidir cómo interpretarlo. Desde este punto de vista la dramatización de poemas supone para el niño el encuentro lúdico con la palabra y con el uso práctico y real de esta. La didáctica de la literatura no solo debe seleccionar textos, como los aportados en este trabajo, con cuya lectura puede disfrutar el discente, sino que también debe sugerirle al docente cómo aprovechar ese texto para desarrollar la competencia literaria de aquel. De esta manera se favorecerá un contacto intenso del educando con textos de literatura infantil que han sido creados para él y que puede vivir con gozo estético a lo largo de su escolarización. 


\section{Referencias bibliográficas}

- Andruetto, T. (2008). Hacia una literatura sin adjetivos. Imaginaria, 242. Obtenido el I3 de octubre desde http://www.imaginaria.com.ar/2008/II/hacia-una-literatura-sin-adjetivos/

- Bernardi, M. (2OII). Poesía y teatro: voces marginales en la marginalidad de la literatura infantil. Alhucema. Revista Internacional de Teatro y Literatura, 25, I77-206.

- Bolton, G. (1986). Freedom and imagination and the implication for teaching drama. En D. Davis y C. Lawrence (Ed.). Gavin Bolton: selected writings (pp. I8-22). Londres: Longman.

- Cerrillo Torremocha, P. C. (Ed.) (2004).¿Dónde está el niño que yo fui? Poemas para leer en la escuela. Madrid: Akal.

- Cervera, J. (1986). Cómo practicar la dramatización con niños de 4 a 14 años. Madrid: Editorial Cincel.

- Cervera, J. (i99o): Aproximación lúdica a la poesía infantil. En P. Cerrillo y J. García Padrino (Ed.). Poesía infantil. Teoría, crítica e investigación (pp. II9-I44). Cuenca: Universidad de Castilla-La Mancha.

- Escandell Vidal, M.V. (r996). Introducción a la Pragmática. Barcelona: Ariel.

- Fábregas, X. (1975). Introducción al lenguaje teatral. Barcelona: Libros de la Frontera.

- Halliday, M.A.K. (1982). Exploraciones sobre las funciones del lenguaje. Barcelona: Médica y Técnica.

- Kelner, L. B. y Flynn, R. M. (2006). A Dramatic Approach to Reading Comprehension: Strategies and Activities for Classroom Teachers. Hannover: Heinemann.

- López Valero, A. , Jerez Martínez, I. y Encabo Fernández, E. (20io). Claves para una enseñanza artístico-creativa: la dramatización. Barcelona: Octaedro.

- Medina, A. (1985). El silbo del aire. Antología lírica infantil(I). El silbo del aire. Antología lírica juvenil (II). Barcelona: Vicens-Vives.

- Montes, G. (2007). La gran ocasión: la escuela como sociedad de lectura. Buenos Aires: Ministerio de Educación, Ciencia y Tecnología.

- Moreno Ramos, J. (1999). Didáctica del vocabulario en la E.S.O.: Estudio empírico. Tesis Doctoral. Universidad de Murcia. 
- Motos, T. (1992). Las técnicas dramáticas: Procedimiento didáctico para la enseñanza de la lengua y la literatura en la Educación Secundaria. Tesis Doctoral. Universidad de Valencia.

- Motos, T. y Tejedo, F. (I999). Prácticas de Dramatización. Madrid: La Avispa.

- Núñez Cubero, L. y Navarro Solano, R. (2007). Dramatización y educación: aspectos teóricos. Teoría de la educación, $\mathrm{I9}, 225^{-2} 5^{2}$.

- O’Neill, C. y Lambert, A. (I982). Drama structures: a practical handbook for teachers. Londres: Hutchinson.

- Owens, R.E. (2003). Desarrollo del lenguaje. Madrid: Pearson Educación.

- Pelegrín, (1997). Poesía española para niños. Madrid: Alfaguara.

- Pérez Gutiérrez, M. (2004). La dramatización como recurso clave en el proceso de enseñanza y adquisición de las lenguas. Glosas didácticas. Revista electrónica internacional, I2, 70-80.

- Seely, J. (1976). In context: language and drama in the secondary school. Oxford: Oxford University Press.

- Tejerina Lobo, I. (1994). Dramatización y teatro infantil. Dimensiones psicopedagógicas y expresivas. Madrid: Siglo XXI.

- Tejerina, I (1997). Juego dramático y educación creadora. En VV.AA. Jornadas Internacionales Teatro y niño. Teatro para ver, Teatro para actuar (Comp.) (pp. 7 ${ }^{\mathrm{I}-8 \mathrm{I}}$ ). Tolosa: Festival Internacional de Marionetas.

- Tough, J. (1987). El lenguaje oral en la escuela: una guía de observación y actuación para el maestro. Madrid: Visor.

- Valenzuela Miranda, J. (2004). La comunicación en la escuela infantil: algunas consideraciones teóricas de utilidad para maestros en ciernes. Didáctica (Lengua y Literatura), ı6, $2 \mathrm{O} 7-233$. 